\title{
Instrumentos e mecanismos de gestão: contribuições ao processo decisório em conselhos de políticas públicas'
}

\author{
Maria Elisabeth Kleba \\ Unochapecó / Programas de Pós-Graduação em Políticas Sociais e Dinâmicas Regionais e em \\ Ciências da Saúde \\ Chapecó / SC - Brasil \\ Dunia Comerlatto \\ Unochapecó / Programa de Pós-Graduação em Políticas Sociais e Dinâmicas Regionais \\ Chapecó / SC - Brasil \\ Kenia Munaretti Frozza \\ Prefeitura Municipal de Coronel Freitas (SC) \\ Coronel Freitas / SC - Brasil
}

\begin{abstract}
A administração pública no Brasil conta com diretrizes e parâmetros estabelecidos em documentos, a exemplo de leis, políticas ou planos, que se constituem em instrumentos para nortear e qualificar a gestão democrática das políticas públicas. A investigação buscou identificar instrumentos e mecanismos de gestão utilizados no processo decisório pelos Conselhos Municipais de Assistência Social e de Saúde em Chapecó (SC). A partir da leitura de atas (2005 a 2009), obtiveram-se como instrumento mais citado os relatórios de prestação de contas, embora esses não evidenciarem articulação com objetivos e metas definidos no plano municipal. Os mecanismos mais utilizados são comissões internas, capacitação, conferências e comunicação com outras organizações. Os conselhos estudados recorrem a instrumentos e mecanismos com potencial para ampliar a participação na gestão pública municipal.
\end{abstract}

Palavras-chave: políticas públicas; conselhos gestores; processo decisório; participação social; instrumentos e mecanismos.

DOI: http://dx.doi.org/10.1590/0034-7612125666

(cc) BY-NC

Artigo recebido em 28 out. 2013 e aceito em 27 jan. 2015.

${ }^{1}$ Artigo produzido a partir de resultados da pesquisa Processos de gestão e impacto da participação social em conselhos de políticas públicas, realizada com subsídios do Edital Universal MCT/CNPq ํㅡ 014/2010. 
Instrumentos y mecanismos de gestión: contribuciones al proceso toma de decisiones en consejos de políticas públicas

El gobierno de Brasil tiene pautas y parámetros establecidos en leyes y otros documentos que guían la formulación de instrumentos para orientar y mejorar la gestión democrática de las políticas públicas. Esta investigación buscó identificar instrumentos y mecanismos de gestión utilizados en la toma de decisión de los Consejos Municipales de Asistencia Social y Salud en Chapecó (Santa Catarina). De la lectura de las actas (2005-09), se obtuvo como instrumento más citado la presentación de cuentas, aunque esto no demuestra la vinculación con los objetivos y metas establecidos en el plan municipal. Los mecanismos más comunes incluyen comités internos, capacitación, conferencias y la comunicación con otras organizaciones. Los consejos estudiados recurren a los instrumentos y mecanismos que tienen el potencial para ampliar la participación ciudadana en la gestión municipal.

Palabras clave: políticas públicas; consejos de gestión; proceso de toma de decisiones; participación social; instrumentos y mecanismos.

Instruments and mechanisms of management: contributions to the decision making process in public policy councils

The public administration in Brazil has guidelines and parameters established in laws, policies or plans that guide the formulation of instruments to guide and assess the democratic management of public policies. The research sought to identify tools and management mechanisms used in decision-making by the Municipal Councils of Social Assistance and Health in Chapecó, Santa Catarina, Brasil. From the reading of the minutes (2005-2009), it was obtained as amost cited instrument the rendering of accounts, although this does not show linkage with aims and targets set at the municipal level. The most common mechanisms include internal committees, training, conferences and communication with other organizations. The councils studied appeal to instruments and mechanisms with the potential to increase public participation in municipal management.

KeYWords: public policies; management councils; decision-making process; social participation; instruments and mechanisms.

\section{Introdução}

Desde a promulgação da Constituição da República Federativa do Brasil, em 1988, cidadãos e sociedade civil organizada passam a ter direito de participar diretamente em processos decisórios relacionados ao Estado brasileiro (Azevedo, 2005). Nessa perspectiva, a gestão das políticas públicas promove maior interlocução entre atores e organizações que, uma vez reunidos em diferentes espaços de interesse público, podem viabilizar processos participativos e democráticos na relação entre governo e sociedade civil.

Experiências brasileiras acumuladas ao longo das últimas décadas no que diz respeito ao alargamento da participação e à construção de espaços públicos, visando a ampliação e a democratização da gestão estatal, têm sido implementadas por vários conselhos gestores de políticas públicas. Em sua maioria instituídas com caráter deliberativo e fiscalizador, essas instâncias se configuram como importante espaço de democracia participativa e de publiciza- 
ção das políticas, contribuindo com "o processo de deslocamento das discussões e decisões da esfera privada para a esfera pública" (Bulla e Leal, 2004:4) e desafiando governo e sociedade no reconhecimento do cidadão ativo em sua missão de corresponsabilidade pela gestão pública (Azevedo, 2005).

Os conselhos gestores, como instâncias participativas e decisórias, promovem aprendizados de convivência democrática, tanto para os atores da sociedade civil quanto os do Estado. A existência dessas instâncias reforça a exigência para que o Estado dê publicidade a suas ações, apresente contas, exponha os critérios que balizam acordos, mas também para que a sociedade civil se qualifique para essa participação. Desse modo, amplia o conhecimento sobre processos que envolvem a gestão pública e possibilita a construção de referenciais adequados para equilibrar a defesa de interesses privados e corporativos com o reconhecimento do caráter coletivo dos direitos implicados (Almeida e Tatagiba, 2012).

Na argumentação de Silva e Oliveira, Pereira e Oliveira (2010:423), os conselhos como organismos públicos - e os conselheiros - como sujeitos coletivos - contribuem para a "democratização da gestão pública, a ampliação quantitativa e qualitativa da participação, a condução coletiva de políticas sociais, a responsabilização de governantes, o controle social proativo e para o intercâmbio de informações entre população e poder local".

Contudo, apesar do potencial de suas contribuições, estudos indicam que grande parte dos conselhos gestores de políticas não tem conseguido se instituir como instâncias de diálogo e de compartilhamento de poder efetivo entre Estado e sociedade civil (Ronconi, Debetir e Mattia, 2011). Dessa forma, correm o risco de se transformar em

órgãos cartoriais (que apenas referendam as decisões do executivo), em mecanismos de legitimação do discurso governamental ou em estruturas formais (sem reuniões frequentes, programas de trabalho, representatividade social, vigor argumentativo, rotinas de capacitação e acesso aos poderes instituídos). (Silva e Oliveira, Pereira e Oliveira, 2010:423)

O estudo de Vázquez e colaboradores (2005:153) reconhece que as políticas de participação social no Brasil "são resultados de anos de luta e pressões pela democratização do Estado" e que essas "levaram a mudanças organizacionais com a criação de diversificadas portas de entrada individuais e coletivas para a participação da população". Não obstante, são muitos os desafios na direção de melhorar a forma de pôr em prática as conquistas estabelecidas no plano legal, incluindo proporcionar à população um conjunto de ações de divulgação e capacitação para fazer valer o uso de mecanismos institucionais de participação e democratização da gestão pública e do controle social.

Para que esse processo de democratização possa avançar, é indispensável que sociedade civil e governos qualifiquem sua intervenção nesses espaços públicos. O desafio em contribuir para a democratização e ampliação da participação na gestão pública — primaz finalidade dos conselhos gestores de políticas públicas - exige que os envolvidos influenciem a dinâmica de funcionamento e os conteúdos da pauta dessas instâncias pela apropriação de informações, meios e condições, de forma a se constituírem efetivamente sujeitos, protagonistas do processo decisório. 
Almeida e Tatagiba (2012) salientam que os conselhos gestores devem redefinir as rotinas de sua dinâmica de funcionamento e o conteúdo das pautas que assumem como seu papel, abrindo espaço em sua agenda para agir como atores políticos, construindo articulações e ampliando seu poder sobre a definição das políticas setoriais.

A partir dessas reflexões, buscamos tecer neste artigo argumentos que possam orientar uma revisão do papel dos conselhos de políticas, apresentando como referência instrumentos de gestão pública, bem como possíveis mecanismos que contribuam para qualificar sua atuação como instância deliberativa e, ao mesmo tempo, ampliem sua capacidade de diálogo com o Estado e a sociedade civil. O artigo apresenta em um primeiro momento uma definição e caracterização dos instrumentos e mecanismos de gestão e de controle social das políticas públicas, indicando instrumentos definidos como norteadores pela legislação. A segunda parte do artigo expõe a metodologia, os resultados e a discussão de uma pesquisa sobre a utilização de instrumentos e mecanismos de gestão pelos conselhos municipais da Assistência Social e da Saúde no processo decisório sobre as políticas públicas em Chapecó (SC).

\section{Instrumentos e mecanismos de gestão pública na perspectiva do controle social}

Associados aos processos de gestão instituídos pelos conselhos municipais no campo das políticas públicas setoriais, compreendemos instrumentos e mecanismos de gestão como partes constitutivas da dinâmica organizacional de todas e quaisquer instituições de natureza pública ou privada. Mais especificamente em organismos de caráter público (como é o caso dos conselhos gestores), defendemos que a utilização de instrumentos e mecanismos no desempenho das competências regimentalmente estabelecidas permite desencadear processos participativos e decisórios mais qualificados de gestão.

Com vistas a delimitar nossa compreensão sobre o que podem ser considerados instrumentos e mecanismos no âmbito do controle social sobre a gestão pública setorial, buscamos na literatura bem como em documentos oficiais referências que pudessem fundamentar uma proposição. Deparamo-nos com uma diversidade de abordagens e definições, as quais não necessariamente se caracterizam como excludentes, mas requerem maior clareza em sua definição para que possam oferecer maior esclarecimento e servir de suporte aos atores envolvidos no processo de tomada de decisão sobre as políticas públicas.

Alguns autores referem os conselhos gestores como "um dos principais instrumentos da gestão descentralizada e participativa da sociedade civil" (Ronconi, Debetir e Mattia, 2011:49). Essa indicação é corroborada pelo Estatuto da Cidade, quando estabelece que,

para garantir a gestão democrática da cidade, deverão ser utilizados, entre outros, os seguintes instrumentos: (I) órgãos colegiados de política urbana, nos níveis nacional, estadual e municipal; (II) debates, audiências e consultas públicas; (III) conferências sobre assuntos de interesse urbano, nos níveis nacional, estadual e municipal. (Brasil, 2002:34) 
Entretanto, os conselhos são salientados como um dos principais instrumentos de participação democrática (Bulla e Leal, 2004), à medida que são e geram espaços de participação, debate e controle social da gestão pública (Ronconi, Debetir e Mattia, 2011; Azevedo, 2005). Azevedo (2005) refere os conselhos gestores ora como mecanismos de cooperação na gestão pública, ora como canais democráticos ou como instrumentos de participação popular, com a finalidade de promover o controle político e social da administração pública, averiguando se as ações executadas por essa administração se pautam em bases legais e atendem ao interesse coletivo, na busca do bem comum.

Por outro lado, constatamos o termo instrumento relacionado por vários autores aos documentos estabelecidos na Constituição Federativa da República Brasileira como fundamentais no planejamento das políticas públicas. Corrêa (2007), em seu estudo sobre a reforma administrativa da gestão pública do estado de Minas Gerais, refere o Plano Mineiro de Desenvolvimento Integrado (PMDI) como instrumento central dessa reforma, "seguido de instrumentos instituídos pela Constituição Federal, quais sejam o Plano Plurianual de Ação Governamental (PPAG), a Lei de Diretrizes Orçamentárias (LDO) e a Lei Orçamentária Anual (LOA)" (Corrêa, 2007:493). Outro instrumento referido pela autora é o contrato de gestão, considerado elo de "ligação entre o núcleo estratégico - responsável pela formulação e avaliação de políticas - e os setores de execução das políticas públicas” (Corrêa, 2007:492).

Brasil, Carneiro e Teixeira (2010), debatendo os novos marcos para o planejamento e as políticas urbanas no âmbito local, salientam o Estatuto da Cidade e os planos diretores como fundamentais para a gestão democrática da cidade. Nessa perspectiva, o plano diretor é reconhecido "como instrumento básico de política urbana" (Brasil, Carneiro e Teixeira, 2010:139), e o Estatuto da Cidade como "referência didática para os governos locais", à medida que em seu art. 4 elenca "os instrumentos da política urbana", bem como "os instrumentos de planejamento municipal, dentre os quais se destacam (...) o plano diretor e os instrumentos orçamentários obrigatórios (plano plurianual, diretrizes orçamentárias e orçamento anual)" (Brasil, Carneiro e Teixeira, 2010:142-143). Machado, Baptista e Lima (2010:2369), em estudo sobre estratégias e instrumentos do planejamento nacional da política de saúde no Brasil, definem instrumentos como "dispositivos que materializam a ação planejadora federal, como os planos e pactos formais", e citam, entre outros, o plano plurianual (PPA), o pacto de gestão e o plano de saúde.

Essas reflexões recuperam o disposto no Estatuto da Cidade (Brasil, 2002) que, em seu capítulo referente aos instrumentos relativos ao planejamento municipal da política urbana, define, entre outros, o plano plurianual, as diretrizes orçamentárias e o orçamento anual, além de planos, programas e projetos setoriais. Esse documento refere ainda que "os instrumentos (...) que demandam dispêndio de recursos por parte do Poder Público municipal devem ser objeto de controle social, garantida a participação de comunidades, movimentos e entidades da sociedade civil" (Brasil, 2002:21).

Nessa perspectiva, o Ministério do Desenvolvimento Social e Combate à Fome, juntamente com o Instituto de Estudos Especiais da Pontifícia Universidade Católica de São Paulo, registra em seu material didático relativo a capacitação para consolidar o Sistema Único de 
Assistência Social (Suas) a necessidade da articulação entre os Planos de Assistência Social e as prioridades definidas nos três instrumentos legais previstos pela Constituição Federal de 1988, quais sejam: Planos Plurianuais (PPAs), Leis de Diretrizes Orçamentárias (LDO) e Leis Orçamentárias Anuais (LOA). A articulação desses instrumentos não é apenas uma exigência do modelo de planejamento, orçamento e gestão previstos na Constituição Federal, mas também uma condição para garantir que, em todos os níveis de governo, os Planos de Assistência Social não sejam "apenas um conjunto de objetivos idealizados e não factíveis ou realizáveis" (Brasil, 2008:16).

Da mesma forma, o Ministério da Saúde estabelece como instrumentos de gestão o Plano de Saúde (PS), a Programação Anual de Saúde (PAS) e o Relatório Anual de Gestão (RAG), necessariamente articulados em cada esfera de governo com o PPA, a LDO e a LOA (Brasil, 2009a:12).

Em relação ao termo mecanismos, poucos autores o abordam no sentido que gostaríamos de imprimir. Entre eles destacamos Vázquez e colaboradores (2005), quando referem os conselhos municipais, as conferências e as ouvidorias como mecanismos diretos de participação em saúde, e a Superintendência de Proteção e Defesa do Consumidor (Procon) como indireto. Para esses autores, tais mecanismos institucionais viabilizam a interação dos cidadãos com o sistema, incorporando suas opiniões ou atividades, bem como o exercício do controle social.

Assumindo essas designações e buscando delimitar a aplicabilidade dos termos instrumentos e mecanismos na qualificação dos processos deliberativos relativos à gestão pública, fazemos referência a dicionários da língua portuguesa. Para Ferreira (2009) e Houaiss, Villar e Franco (2009), instrumento pode ser entendido como "objeto usado para executar algo; apetrecho, ferramenta” (Houaiss, Villar e Franco, 2009:427), considerado em sua função ou utilidade e, ainda, como "recurso empregado para se alcançar um objetivo, conseguir um resultado" (Ferreira, 2009:1114). Por sua vez, mecanismo é definido como "conjunto de elementos envolvidos no funcionamento de qualquer estrutura ou sistema" (Houaiss, Villar e Franco, 2009:494) e "disposição das partes constitutivas de uma máquina, (...) funcionamento orgânico, processo de funcionamento" (Ferreira, 2009:1298).

Outra referência que pode qualificar a delimitação dessas duas categorias é o artigo de Ollaik e Medeiros (2011) sobre instrumentos governamentais como pauta para a agenda de pesquisas. Para esses autores, tais instrumentos se caracterizam tanto como método, "por meio do qual a ação coletiva é estruturada para lidar com um problema público" (Ollaik e Medeiros, 2011:1945), quanto como instituição social, que reúne um conjunto de "regras e procedimentos mais ou menos coordenados que governam as interações e os comportamentos dos atores e das organizações" (Ollaik e Medeiros, 2011:1949). Concordamos em parte com essa designação, em especial quando os autores assinalam que instrumentos governamentais dão estrutura e influenciam as políticas públicas, mas consideramos que a distinção entre instrumentos - mais relacionados às regras - e mecanismos - mais relacionados às ações - pode contribuir para apoiar a atuação dos sujeitos envolvidos nos processos de gestão e controle social das políticas públicas. 
Com base nos argumentos descritos pelos autores e nas informações empíricas alcançadas no estudo sobre processo decisório e impacto da participação social na gestão das políticas públicas, com destaque à pesquisa sobre instrumentos e mecanismos utilizados pelos conselhos municipais aqui delimitados, propomos "um ensaio de definição" para esses conceitos. Compreendemos instrumentos como base e fundamento que compõem o ordenamento oficial/ legal e legítimo para orientar o processo decisório na gestão de políticas, instruindo sua formulação, deliberação, implementação, fiscalização e avaliação. Podemos citar, por exemplo, leis, políticas, normatizações, planos, programações anuais (instrumentos com caráter regulador/ propositivo) ou relatórios (com caráter analítico/indicativo), os quais alimentam e concretizam o processo contínuo de planejamento na gestão pública. De forma complementar, compreendemos mecanismos como certos movimentos e modos de operar, com vistas a ampliar e qualificar o debate, possibilitando maior compreensão sobre as questões em pauta e favorecendo processos de tomada de decisão mais coerentes com demandas e potencialidades identificadas, sem prejuízo das orientações e normativas legais. Assim, os mecanismos se constituem como estratégias, ações e dinâmicas aplicáveis pelos conselheiros/conselhos ao processo decisório, com vistas a aumentar sua capacidade de exercer, efetivamente, o controle social sobre a gestão de políticas públicas, de acordo com o previsto legal e regimentalmente.

Concordamos com Ollaik e Medeiros (2011:1949), ao referirem que instrumentos indicam um conjunto de regras que conduzem as interações de atores e organizações, oferecendo "um contexto estável dentro do qual as incertezas são reduzidas e a ação coletiva é estruturada". Nessa perspectiva,

(...) os instrumentos de políticas públicas (...) dão estrutura às políticas públicas e as influenciam, (...) determinam parcialmente quais recursos serão usados e por quem, (...) permitem que formas de ação coletiva estabilizem e façam o comportamento dos atores ser mais previsível e provavelmente também mais visível. Deste ponto de vista, a escolha do instrumento é um tema político, pois estrutura o processo e seus resultados. Os instrumentos não são escolhas puramente técnicas e produzem efeitos específicos, independentemente de seus objetivos declarados. Os instrumentos estruturam as políticas públicas segundo suas lógicas inerentes (...). (Ollaik e Medeiros, 2011:1949)

Assumimos aqui como principais instrumentos de controle social sobre a gestão de políticas nas áreas da assistência social e da saúde, além de sua legislação básica, os documentos de planejamento e orçamento governamentais e setoriais, abordados a seguir.

\subsection{O PPA como instrumento orientador na gestão das políticas públicas}

A Constituição da República Federativa do Brasil (Brasil, 1988) prevê como instrumento essencial de planejamento do governo o Plano Plurianual (PPA), no qual devem constar metas de investimentos e despesas para o período de quatro anos, estruturadas na forma de programas. 
O arcabouço institucional do PPA,

(...) inclusive os mecanismos criados para a sua gestão, constitui-se em um grande esforço de consolidação da função planejamento na administração pública, e veio ao encontro do dispositivo constitucional que estabeleceu três instrumentos de planejamento: o PPA, a Lei de Diretrizes Orçamentárias (LDO) e a Lei Orçamentária Anual (LOA). (Culau, 2004:13)

Para Paulo (2010:172), é possível afirmar que a Constituição atribuiu ao PPA um papel central de organização da ação do Estado, pois submete e orienta a elaboração dos demais documentos de planejamento (planos e programas nacionais, regionais e setoriais - art. 165, $\S 4^{\circ}$ ) e de orçamento (LDO e LOA — art. 166) às suas disposições.

Garcia (2012) ressalta a necessária compatibilidade entre LDO, orçamentos anuais e PPA, da mesma forma, qualquer plano ou programa nacional, regional e setorial previstos na Constituição ou ainda instituídos durante um período de governo.

Nenhum investimento cuja execução ultrapassar um exercício financeiro poderá ser iniciado sem prévia inclusão no PPA ou sem lei que autorize tal inclusão, sob pena de crime de responsabilidade. As emendas parlamentares à LDO e ao orçamento somente serão apreciadas pela comissão mista pertinente do Congresso Nacional se compatíveis com a lei que institui cada PPA. Ou seja, este plano é concebido com evidente caráter coordenador das despesas governamentais e o poder de subordinar a seus propósitos todas as iniciativas que não tenham sido inicialmente previstas. (Garcia, 2012:431)

O PPA foi concebido como instrumento estratégico de planejamento e de gestão pública, à medida que estabelece compromisso político entre os Poderes Executivo e Legislativo, para além do mandato presidencial (Paulo, 2010). Culau (2004) salienta que a proposta do PPA foi concebida com vistas a orientar um plano de desenvolvimento abrangente, capaz de produzir mudanças sobre a realidade nacional, organizando, sob a forma de programas, os problemas e potencialidades atribuídos ao Estado.

Com vistas a aperfeiçoar a aplicação do PPA como instrumento efetivo de gestão das políticas, o Ministério do Planejamento, Orçamento e Gestão cria, em 1997, um grupo de trabalho interministerial (GTI) integrado por representantes de diversos órgãos. Esse grupo reforça a compreensão do planejamento como processo permanente que deve ter em vista "o desenvolvimento econômico e social e a contínua melhoria das condições de vida da população" (Garcia, 2012:432). Para tanto, deve partir de um diagnóstico da situação, identificando e selecionando problemas prioritários, sobre os quais são definidos objetivos, formuladas estratégias e diretrizes, que reúnem ações organizadas em programas.

Para o Ministério do Planejamento, Orçamento e Gestão (Brasil, 2009b), a gestão voltada ao alcance de resultados, criando valor público, deve buscar o atendimento de demandas e expectativas dos beneficiários, sejam cidadãos ou organizações. Entre os fatores que influenciam a produção de resultados, o Ministério refere consciência estratégica e liderança, que 
inclui capacidade de formulação compartilhada, definição de ações, procedimentos, competências e responsabilidades, bem como mecanismos de monitoramento e avaliação.

Paulo (2010) reforça que, ao orientar uma prática de gestão voltada para resultados, o PPA estabeleceu o compromisso do Estado em alterar a realidade e não apenas em prestar serviços. A definição de programas permite identificar a sobreposição de esforços, bem como eventuais parcerias como oportunidades, seja entre instituições públicas, seja com entidades privadas. Da mesma forma, a gestão por programas favorece o controle externo sobre a execução das políticas. Segundo o autor, "o uso do PPA por parte dos órgãos de fiscalização demonstra cabalmente a contribuição do PPA à transparência do governo" (Matsuda et al., apud Paulo, 2010:179). Garcia (2012) destaca o PPA como instrumento que explicita as intenções de gasto do governo, garantindo maior coerência às ações ao longo do tempo, e que organiza as intervenções parlamentares nos orçamentos.

No entanto, o PPA ainda não foi reconhecido como um efetivo instrumento de planejamento e gestão estratégica. "Para que se cumpra a Constituição Federal de maneira efetiva, o Plano Plurianual precisa ser incorporado ao debate político decisório" (Paulo, 2010:182). Da mesma forma, precisa incorporar elementos que instrumentalizem e apoiem o exercício da gestão cotidiana sobre programas e respectivas ações, o que implica a definição mais clara de responsabilidades, bem como a organização, o conhecimento e a informação adequados à condução de processos complexos, que possam

(...) dar conta das novidades contidas na proposta e da complexidade do mundo real. Neste, não predominam os problemas estruturados, passíveis de serem enquadrados em setores nos quais se estrutura a administração pública e nas disciplinas que organizam o conhecimento acadêmico. (Garcia, 2012:442)

Analisando os textos dos PPAs Nacionais de 2004-07 e 2008-11, Garcia (2012) aponta como um dos desafios a superação das práticas programáticas que priorizam a inclusão de ações organizadas de forma compartimentada nas caixinhas dos organogramas ministeriais, respondendo a interesses dos feudos corporativo-burocráticos, "enquanto os problemas complexos - cujo eficaz enfrentamento exige ações de diversas naturezas, nunca encontradas em uma mesma área setorial - que povoam a agenda governamental, demandam programas multissetoriais" (Garcia, 2012:443).

\subsection{Instrumentos e mecanismos de gestão e controle social no âmbito das políticas de assistência social e de saúde}

A gestão das políticas públicas no município tem entre seus desafios não apenas a inclusão efetiva da sociedade no processo de tomada de decisão, mas também a utilização de instrumentos e mecanismos de planejamento e gestão que garantam maior alinhamento com as políticas nacionais e o controle social previsto constitucionalmente. No caso da assistência so- 
cial e da saúde, setores da administração pública selecionados para este estudo de casos, leis e demais documentos regimentais e normativos, de âmbito nacional, estadual e municipal, definem diretrizes, princípios, atribuições e parâmetros de gestão que devem ser considerados pelos atores envolvidos nesse processo.

A política de assistência social está expressa constitucionalmente como política pública não contributiva - dever do Estado e direito de todo cidadão que dela necessitar. Orienta-se pela Lei Orgânica da Assistência Social (Loas), no 8.742, de 7 de dezembro de 1993, alterada pela Lei no 12.435 , de 6 de julho de 2011 — DOU de 7/7/2011. A gestão das ações nessa área se processa sob a forma de sistema descentralizado e participativo, denominado Sistema Único de Assistência Social (Suas) e suas ações têm como base as orientações da Política Nacional de Assistência Social (PNAS), aprovada pelo Conselho Nacional de Assistência Social (CNAS) em 2004, e a Resolução no 33, de 12 de dezembro de 2012, que aprova a Norma Operacional Básica do Sistema Único de Assistência Social (NOB/Suas).

Os princípios organizativos do Suas se configuram pela universalidade; gratuidade, integralidade da proteção social, intersetorialidade e equidade. Encadeados a esses princípios, o Suas define eixos estruturantes imprescindíveis à execução da política de assistência social, tais como: matricialidade sociofamiliar; descentralização político-administrativa e territorialização; relação entre Estado e sociedade civil; financiamento; controle social; política de recursos humanos; informação, monitoramento e avaliação (Brasil, 2013).

Destaca-se que, para a implementação e aperfeiçoamento do Suas, o eixo "informação, monitoramento e avaliação" é essencial na busca de resultados em torno da produção de informações e conhecimentos para gestores, trabalhadores e usuários, contribuindo com a qualificação do controle social e a democratização da política. São essas informações que evidenciam a eficiência, eficácia e efetividade e indicam a qualidade das ações e dos serviços na área da assistência social, fornecendo elementos para fundamentar a tomada de decisão, tanto da gestão, quanto do controle social. Entre outros instrumentos de planejamento, o Suas salienta o Plano de Assistência Social e o Relatório Anual de Gestão, os quais devem estar articulados ao PPA, à LDO e LOA do município (Brasil, 2013).

A política da saúde tem sua ordem organizativa demarcada a partir dos anos 1990, ao criar o Sistema Único de Saúde (SUS) — por meio da Lei ํㅜㅇ.080, de 19 de setembro de 1990 - e definir as condições para a promoção, proteção e recuperação da saúde, pautadas na compreensão de que a saúde é determinada por uma série de fatores presentes no cotidiano da vida, quais sejam: alimentação, moradia, saneamento básico, meio ambiente, trabalho, educação, lazer (Brasil, 1990). Essa lei define ainda os princípios que orientam a organização e o funcionamento dos serviços de saúde, tais como: universalidade de acesso; integralidade e igualdade de assistência; preservação da autonomia das pessoas; direito à informação sobre sua saúde e sobre os serviços disponíveis; participação da comunidade; descentralização político-administrativa, entre outros.

A participação da comunidade, uma das três diretrizes do SUS definida pela Constituição Federal, é reiterada pela Lei no 8.142, de 28 de dezembro de 1990, que estabelece os Conselhos e as Conferências de Saúde como espaços formais de sua efetivação na gestão em 
saúde. Importante ressaltar que a legislação do SUS prevê um processo de planejamento "ascendente e integrado, do nível local até o federal, ouvidos os respectivos Conselhos de Saúde" (Brasil, 2011), e institui como instrumentos de gestão o Plano de Saúde (PS), a Programação Anual de Saúde (PAS) e o Relatório Anual de Gestão (RAG), que devem ser compatíveis com o PPA, a LDO e a LOA (Brasil, 2009a).

Em relação às políticas de saúde, o Pacto pela Saúde (Brasil, 2006) define, entre as responsabilidades dos municípios relativas ao planejamento e gestão do SUS, a formulação, o gerenciamento, a implementação e a avaliação permanente do planejamento participativo e integrado, orientado por problemas e necessidades em saúde, construindo nesse processo o Plano de Saúde, o qual deve ser submetido ao Conselho de Saúde para sua aprovação. O Plano de Saúde é referido pelo Ministério da Saúde no Sistema de Planejamento do SUS (PlanejaSUS) como o principal instrumento de gestão, sendo base para definição e implementação de todas as iniciativas em âmbito da saúde, ao mesmo tempo que deve orientar a definição do Plano Plurianual (PPA). Por sua vez, o Relatório Anual de Gestão é o instrumento que possibilita a avaliação contínua dos resultados alcançados pela implementação do Plano de Saúde, indicando eventuais ajustes necessários e orientando a elaboração da Programação Anual subsequente (Brasil, 2009a).

Como instrumentos interligados, interdependentes e de caráter contínuo, o Plano de Saúde, a Programação Anual e o Relatório de Gestão têm entre suas finalidades apoiar o gestor na condução do SUS, contribuir para o aperfeiçoamento da gestão participativa e apoiar a participação e o controle social (Brasil, 2009a).

Em âmbito nacional, no que se refere ao Conselho Nacional de Assistência Social (CNAS), o mesmo foi instituído pela Loas, em seu art. 17, como órgão superior de deliberação colegiada, responsável pela coordenação da Política Nacional de Assistência Social, vinculado à estrutura da administração pública federal. As competências atribuídas ao CNAS, como Conselho superior nessa área de política pública, e as que, de modo extensivo e específico, também são atribuídas aos conselhos municipais, imprimem a necessidade de apropriação de instrumentos e mecanismos operativos para subsidiar o desempenho das funções estabelecidas e movimentar sua dinâmica de funcionamento.

Em âmbito local, o Conselho Municipal de Assistência Social de Chapecó (SC) (CMAS) foi criado pela Lei Municipal no 3.654, de 31 de agosto de 1995, como órgão consultivo e deliberativo do Sistema Municipal de Assistência Social, de caráter permanente, responsável pela formulação de estratégias e controle da execução da política em nível local, e reúne representantes do governo e da sociedade civil para discutir, estabelecer normas e fiscalizar a prestação de serviços sociais públicos e privados no município. Também com caráter deliberativo, o Conselho Municipal de Saúde de Chapecó (CMS) foi instituído pela Lei Municipal no 3.290/1991, sendo regido atualmente pela Lei Municipal no 6419/2013, em termos de sua composição, atribuições e estrutura de funcionamento. Tais fóruns se vinculam ao respectivo órgão gestor do município, com competência para deliberar e acompanhar a execução da política setorial, o que inclui a apreciação e aprovação da proposta orçamentária. Desse modo, a gestão dessas políticas passa a ser compartilhada entre poder público e socie- 
dade civil (organizada por meio de movimentos sociais, entidades e profissionais da área), na busca de consolidar o caráter participativo para uma gestão democrática e qualificada. Um processo qualificado de gestão compartilhada exige a incorporação de instrumentos e mecanismos como estratégias para respaldar a tomada de decisão, bem como o acompanhamento da implementação das políticas.

Reconhecer que o processo decisório dos conselhos gestores deve estar balizado em documentos como o PPA e os planos setoriais como efetivos instrumentos de planejamento e gestão pública aponta para a importância de verificar sua utilização nessas instâncias como norteadores no debate e no exercício do controle social. Nosso interesse reside em reconhecer, no âmbito do município de Chapecó (SC), quais os instrumentos e mecanismos utilizados pelos conselhos de Assistência Social e de Saúde, com vistas a potencializar o desempenho de seu papel.

\section{Procedimentos metodológicos}

Como parte do estudo ampliado de longa duração que focaliza a efetividade dos processos de gestão em conselhos de políticas públicas, considerando-se o protagonismo dos sujeitos, a dinâmica do processo decisório e o impacto sobre as políticas públicas no município de Chapecó (SC), associa-se este estudo focalizado no reconhecimento dos instrumentos e mecanismos de gestão utilizados pelos conselhos municipais na dinâmica do processo decisório. Ambos os estudos estão vinculados ao Núcleo de Iniciação Científica em Políticas Públicas e Participação Social da Universidade da Região de Chapecó (Unochapecó), caracterizando-se como estudo de casos, ao compreender o Conselho Municipal de Assistência Social (CMAS) e o da Saúde (CMS) como sujeitos-objeto da pesquisa, na abrangência do município de Chapecó.

Com vistas a reconhecer os instrumentos e mecanismos de gestão utilizados pelos conselhos municipais na dinâmica do processo decisório, desenvolveu-se um trabalho de campo, no período de agosto de 2010 a junho de 2011, guiado por meio da: (1) organização de documentos relacionados à atuação dos conselhos na dinâmica do processo decisório, tais como lei de criação, regimento interno e atas; (2) leitura de 112 atas (48 da saúde e 64 da assistência social) para identificar instrumentos e mecanismos utilizados na dinâmica do processo decisório.

O método de tratamento das informações orientou-se pela análise de conteúdo, com base na modalidade da análise temática. Para Minayo (2007:316), proceder a "uma análise temática, consiste em descobrir os núcleos de sentido que compõem uma comunicação, cuja presença ou frequência signifiquem alguma coisa para o objeto analítico visado".

Operacionalmente, a referida análise se desdobra em: pré-análise, que consiste na escolha dos documentos a serem analisados (para fins deste estudo, os documentos são as leis, os regimentos internos e as atas de reuniões, mais especificamente); na exploração do material, com vistas a alcançar o núcleo de compreensão do texto, recortando unidades de registro que 
contemplem expressões significativas; no tratamento dos resultados obtidos e sua interpretação, etapa em que se colocam em relevo os significados, inter-relacionando-os com o quadro teórico inicialmente proposto (Minayo, 2007:317).

\section{Resultados e discussão}

O estudo sobre instrumentos e mecanismos utilizados pelos conselhos municipais da assistência social e da saúde no processo decisório em Chapecó (SC) evidencia uma prática restrita em relação a gestão de políticas públicas. No caso da assistência social, o debate se concentra na aprovação de convênios, a partir dos pareceres de comissões internas sobre o pedido de credenciamento e recredenciamento de entidades para a prestação de serviços. No caso da saúde, ganha maior espaço a aprovação de relatórios, ou ainda a análise e aprovação de demandas ou propostas de ações/programas governamentais, com vistas a garantir a transferência de recursos do nível nacional para o municipal.

Em relação aos instrumentos que devem orientar o processo decisório, evidenciamos uma lacuna no que se refere a documentos legais estabelecidos pelas diferentes esferas governamentais para a área. Em nosso estudo, identificamos leis, planos, programações anuais e relatórios como pauta em caráter informativo ou deliberativo, sem, no entanto, indicarem efetiva articulação entre esses instrumentos, e tampouco sua utilização como orientação contínua do processo de planejamento e avaliação das políticas, programas e ações desenvolvidos no município.

Em estudo realizado sobre o conhecimento de conselheiros relativo a suas funções, Saliba e colaboradores (2009:1373) consideram o papel mais importante dos Conselhos Municipais de Saúde "a participação na elaboração e aprovação dos instrumentos de gestão, acompanhamento e avaliação da saúde". Apesar de 70\% dos conselheiros entrevistados referirem não sentir dificuldades em analisar documentos, relatórios e orçamentos, um grande percentual demonstrou falta de conhecimento real sobre suas funções e desconhecia documentos como o Regimento Interno do Conselho.

Em Chapecó, nos cinco anos analisados, apesar de a Lei Orgânica da Assistência Social (Loas) ser mencionada cinco vezes nas atas do CMAS, sua menção é vinculada essencialmente a informações trazidas pela presidente do Conselho sobre a necessidade de sua implementação no município, ou ainda ao debate sobre a necessidade de capacitação dos atores envolvidos para sua compreensão, e não para fundamentar o debate ou orientar as deliberações. Por sua vez, a Lei Orgânica da Saúde (LOS) não é mencionada nas atas do CMS no período analisado.

O uso do instrumento "relatório de prestação de contas", posicionado em primeiro lugar na tabela 1, explicita, em certa medida, características "fiscalizatória e informativa" na qualificação dos debates e decisões que ocorrem nas reuniões dos conselhos estudados. Essa análise adquire maior relevância, se considerarmos que a prestação de contas aparece dissociada da avaliação dos resultados produzidos pelas ações e programas, não contribuindo, dessa forma, 
na geração de informações qualificadas para a tomada de decisões, como na definição de prioridades e de investimentos para o Plano Municipal ou a Programação Anual.

Tabela 1

Instrumentos utilizados e frequência de sua indicação nas atas das reuniões dos Conselhos Municipais da Saúde (CMS) e da Assistência Social (Cmas) de Chapecó (SC), 2005 a 2009

\begin{tabular}{|lccc|}
\hline Instrumentos & CMS & CMAS & Total \\
\hline Relatório de prestação de contas & 26 & 78 & 104 \\
Relatório de gestão & 7 & 3 & 10 \\
Plano municipal & 8 & 7 & 15 \\
Plano de ações e metas & 5 & 3 & 8 \\
Planos de temas/ações específicas & 3 & 2 & 5 \\
Programação anual & 2 & 4 & 6 \\
Pactos de gestão e de indicadores & 7 & & 7 \\
Lei orgânica (da assistência social) & & 5 & 5 \\
Outros & 1 & 1 & 162 \\
Total & 59 & 103 & 2 \\
\hline
\end{tabular}

Fonte: Levantamento efetuado pelas autoras (2011)

Por sua vez, o Plano Municipal é referido nas atas apenas como pauta para sua deliberação; no caso da saúde, apenas no primeiro ano de governo, e no caso da assistência social, a partir do segundo ano. A menção ao Plano se restringe a sua apresentação e submissão à aprovação do conselho pelo gestor da área, bem como a algumas falas dos conselheiros que questionam, solicitam informações ou sugerem a inclusão de metas para sua deliberação. Duas questões se colocam a partir dessa constatação: primeira, de que a deliberação sobre o Plano deve ocorrer no primeiro ano de governo, período em que deve ser submetido ao debate e aprovação em todos os municípios brasileiros, uma vez que os planos setoriais devem estar em sintonia e, ao mesmo tempo, servir de base para a elaboração do PPA; segunda, de que não há menção ao Plano na perspectiva de instrumentalizar o acompanhamento e a avaliação da implementação das políticas no município.

O PlanejaSUS salienta a interdependência dos três instrumentos de gestão — Plano de Saúde (PS), Programação Anual de Saúde (PAS) e Relatório Anual de Gestão (RAG) —, devendo o RAG estabelecer a correlação entre metas, resultados obtidos e recursos utilizados. Dessa forma, esse fornece subsídios

(...) para a tomada de decisão, contribuindo para a visibilidade da gestão. Representa também uma demonstração do que se alcançou em relação ao que está explicitado no PS, além de ser um instrumento que viabiliza o controle social. (...) as PAS e os RAG precisam ser instrumentos 
objetivos, práticos, conformados de modo a facilitar o rápido e adequado entendimento. Constituem-se assim ferramentas que devem possibilitar a qualificação das práticas gerenciais do SUS (...). (Brasil, 2009a:15)

Da mesma forma, nas atas dos conselhos pesquisados consta apenas uma referência ao Plano Plurianual do município, quando no CMAS são apresentadas e debatidas propostas do PPA, com vistas a seu encaminhamento para que o gestor possa incluí-las na elaboração do Plano Municipal dessa área.

Para Silva, Castro e Serpa (2006:11), embora a legislação não explicite que o gestor municipal deva ouvir os conselhos municipais na elaboração do PPA, "seria desejável e até salutar ouvir essas formas de representação municipal, de forma a garantir, mesmo que indiretamente, alguma participação popular na elaboração e discussão do PPA". Além de assegurar maior legitimidade, tal iniciativa poderia promover junto a diferentes atores sociais maior corresponsabilidade e comprometimento no desenvolvimento das ações planejadas.

A participação efetiva da população na elaboração do PPA e da LDO vai depender da vontade e da orientação política do governante local. A LRF sugere que o governo municipal crie esse espaço de participação popular, de forma a garantir o desenvolvimento de um planejamento que resulte na democratização do saber e do poder, estimulando a cooperação e a corresponsabilidade tanto na hora de tomar decisões, como no momento de implementá-las e avaliá-las. (Silva, Castro e Serpa, 2006:11-12)

Sendo instrumento orientador e articulador das políticas setoriais, o PPA deve nortear o aperfeiçoamento da gestão, favorecendo a participação da comunidade, à medida que indica resultados pretendidos para cada programa previsto, estabelece metas para as ações que os integram e quantifica os respectivos custos. Desta forma, facilitaria o monitoramento da execução e a avaliação dos resultados, e "a avaliação de desempenho passaria a ser critério para a alocação de recursos orçamentários em anos seguintes” (Garcia, 2012:432).

A partir da identificação dos instrumentos utilizados pelos conselhos gestores pesquisados, buscamos registrar movimentos e modos de operar em sua dinâmica, que pudessem indicar mecanismos de qualificação do debate e, consequentemente, do processo de tomada de decisão.

A tabela 2 evidencia uma gama de mecanismos acionados pelos conselhos estudados como apoiadores na dinâmica dos debates e das decisões em seus ambientes internos e externos. Dentre esses, salientamos como resultados significativos em nosso estudo quatro mecanismos essenciais:

v a comissão interna, como espaço que viabiliza aprofundar o debate e agilizar os processos a partir de demandas ou tarefas específicas;

v a capacitação, que constitui iniciativa para fortalecer a capacidade de os conselheiros acessarem e utilizarem melhores instrumentos, dados e informações, bem como desenvolverem habilidades requeridas em processos de comunicação; 
v a conferência, como fórum consultivo que amplia a participação da sociedade no processo, incluindo-a no reconhecimento de necessidades e potencialidades, na definição de diretrizes e na proposição de estratégias para a área da política pública; e

- iniciativas de comunicação, seja com o gestor da área, seja com representantes de outros setores da administração pública ou ainda com organizações (prestadoras de serviço e/ou membros efetivos no respectivo conselho gestor).

\section{Tabela 2}

Mecanismos utilizados e frequência de sua indicação nas atas das reuniões dos Conselhos Municipais da Saúde (CMS) e da Assistência Social (Cmas) de Chapecó (SC), 2005 a 2009

\begin{tabular}{|lrrr|}
\hline Mecanismos & CMS & CMAS & Total \\
\hline Comissão interna & 46 & 76 & 122 \\
Exposição programa e/ou ação governamental & 102 & 10 & 112 \\
Conferência & 10 & 45 & 55 \\
Exposição de entidades prestadoras e/ou intersetorial & 27 & 2 & 29 \\
Capacitação de conselheiros & 4 & 17 & 21 \\
Exposição de entidades representadas no CMS & 15 & - & 15 \\
Articulação com outros conselhos & 10 & 1 & 11 \\
Apoio operacional para funcionamento do CMS & 6 & - & 6 \\
Comissão específica (não regimental) e consulta a especialista & 3 & 3 & 6 \\
Reuniões descentralizadas & - & 7 & 7 \\
Fórum ampliado & 2 & - & 2 \\
Convite à esfera estadual/federal & 2 & 227 & 388 \\
Total & 27 & 2 \\
\hline
\end{tabular}

Fonte: Levantamento efetuado pelas autoras (2011).

Em relação ao primeiro mecanismo - com predominância no CMAS —, ambos os conselhos preveem em sua legislação e possuem efetivamente organizadas comissões internas (de normas; prestação de contas; visita, acompanhamento e fiscalização; entre outras). Salientamos que, se, por um lado, essas instâncias agilizam os processos e viabilizam que o Conselho desempenhe melhor suas atribuições, por outro lado, não têm conseguido encaminhar à plenária do Conselho pareceres ou outras formas de comunicação mais elaboradas, de forma a subsidiar decisões mais qualificadas. O espaço do Conselho corre o risco de restringir seu poder, quando aprova decisões sem aprofundar o conhecimento sobre o tema em pauta.

Por sua vez, a capacitação, também com predominância no CMAS, expressa preocupação com uma estruturação de base formativa dos conselheiros, com vistas a melhorar o desempenho de suas competências regimentais, em especial em face da necessidade de o gestor implantar o Sistema Único da Assistência Social. Já no CMS, os eventos de capacitação 
ocorrem a partir de iniciativas da presidência do conselho, inserindo momentos de estudo nas reuniões mensais com participação de convidados externos.

As conferências - terceiro mecanismo identificado como relevante ao processo decisório - surgem na pauta em especial como corresponsabilidade ou tarefa a ser assumida pelos conselheiros no processo de organização e implementação. Aspecto relevante a salientar é a realização de pré-conferências nas áreas das políticas analisadas, bem como a interlocução com outras áreas da administração pública com vistas à realização de conferências conjuntas ou a participação dos conselheiros em outros espaços, oportunizando diálogos intersetoriais.

As conferências municipais temáticas são encontros periódicos e amplos em que se deve estimular a participação das organizações da sociedade civil e do poder público. Têm por objetivo avaliar e definir diretrizes referentes à política municipal e à atuação do conselho municipal. Para atingi-lo, são necessárias a ampla convocação das instituições e a garantia da prestação de contas do poder público municipal. Nesse sentido, o conselho tem papel fundamental na organização das conferências para garantir o alcance de suas metas. (...) No âmbito do conselho, devem ser programadas (...) ações periódicas de prestação de contas, a fim de garantir o monitoramento, a avaliação e o redesenho das políticas. (Santos, 2003:73)

Sendo um importante mecanismo de qualificação do debate para a tomada de decisões e um marco na orientação da formulação e avaliação das políticas, chama a atenção a ausência das resoluções das conferências como pauta das atas que sucedem sua realização no município. São esses espaços que oportunizam publicização do diagnóstico das necessidades e potencialidades locais, incluindo as condições dos serviços prestados e os resultados das políticas desenvolvidas pelo poder público. Nessa perspectiva, suas resoluções deveriam nortear a definição das prioridades e respectivas estratégias para o Plano Municipal.

Para Saliba e colaboradores (2009), o distanciamento entre a conferência e o conselho, bem como sua redução a um fórum que vocaliza demandas mais restritas de trabalhadores e usuários podem estar provocando o afastamento do conselho de seu projeto original, "que é o de se tornar um espaço de negociação e discussão entre grupos de interesse, com a promessa de tornar as políticas de saúde mais responsivas aos interesses dos usuários" (Stralen apud Saliba et al., 2009:1376-1377).

Já o quarto mecanismo destacado, com maior ênfase no Conselho Municipal da Saúde, apresenta diferentes iniciativas no que concerne a manter comunicação e se articular com diferentes atores e organizações na perspectiva do interesse público. A exposição de programas e ações por parte do governo ou de prestadores de serviços, a exposição de convidados sobre temas específicos, a apresentação de entidade representada no Conselho ou ainda a participação de outros conselhos gestores nas reuniões passam a estabelecer estratégias valiosas para aglutinar informações, oportunizando ainda firmar relações intersetoriais.

As articulações promovidas pelo espaço aberto à comunicação de entidades geram oportunidades para o empoderamento político, pois criam ambientes favoráveis à ampliação da participação social nas decisões políticas relevantes. Da mesma forma, promovem intera- 
ção e apoio mútuo "entre indivíduos e organizações, entre organizações governamentais e não governamentais, visando melhorar as condições de vida e o alcance de objetivos pessoais e coletivos" (Kleba e Wendhausen, 2009:741).

Landerdhal e colaboradores (2010) reforçam que os conselheiros municipais, por desempenharem um papel fundamentalmente público,

deveriam sair do âmbito interno da burocracia e instituir mecanismos mais eficientes de contato com as próprias entidades representadas nos conselhos, a fim de que a população os conheça de fato e de direito como um dos mecanismos importantes do controle social. (Landerdhal et al., 2010:2434)

Almeida e Tatagiba (2012) ressaltam a importância de os conselheiros travarem uma luta não no interior dos conselhos, mas sim no interior do estado com vistas a fortalecer o poder dessas instâncias e ampliar o reconhecimento da legitimidade de seu papel no processo deliberativo sobre as políticas públicas. Para essas autoras, o fortalecimento da face pública dos conselhos implica, sem deixar de consolidar sua posição no interior do Estado, ampliar seus vínculos efetivos com a sociedade civil, alargando seus elos com diferentes grupos sociais, a fim de mobilizá-los na luta em torno da produção de políticas.

Para Ronconi, Debetir e Mattia (2011), os conselhos gestores podem se constituir em instâncias de coprodução de políticas, à medida que envolvem a participação ativa dos cidadãos na produção dos serviços públicos. Nesse sentido, o Estado passa a assumir o papel de fomentador e articulador de redes de coprodução social, estabelecendo parcerias efetivas entre administração pública, organizações sociais e população, na perspectiva de compartilhamento de responsabilidades.

Os conselhos gestores de políticas públicas se configuram como instâncias comunicativas e de articulação entre as esferas de governos e a sociedade, uma vez que são constituídos na perspectiva de instaurar e difundir processos participativos, democráticos e decisórios. Nessa lógica, assumem protagonismo efetivo como ator público na construção social da realidade e no (re)desenho das relações de poder.

\section{Considerações finais}

Os conselhos gestores de políticas públicas se constituem instâncias para promover a democracia participativa e, com isso, deliberar em defesa dos interesses coletivos e do bem comum. A construção de espaços públicos pode alcançar patamares qualificados de debates e decisões, quando se estabelece a institucionalização de instrumentos e mecanismos a serem utilizados em seus processos de gestão, com vistas a potencializar os fluxos participativos, decisórios e de controle social em face das ações que são executadas. Ao reconhecer os instrumentos e os mecanismos utilizados pelos Conselhos Municipais da Assistência Social e da Saúde no contexto de Chapecó (SC), visualiza-se a apropriação de diferentes e significativos ordenamentos e modos de operar na busca de qualificar os processos de tomada de decisão. 
Entre os instrumentos utilizados, destaca-se o relatório de prestação de contas, sem contudo evidenciar articulação entre investimentos realizados e o alcance de metas traçadas nos planos municipais. Os planos aparecem pouco como foco de debates e em menor proporção como instrumento efetivo para apoiar argumentos ou para acompanhar a implementação da gestão. Em relação aos mecanismos utilizados para qualificar o processo decisório, as comissões temáticas específicas e a exposição de programas por agentes governamentais indicam formas de viabilizar maior apropriação dos conselheiros sobre conteúdos da pauta. Compreende-se que os instrumentos e mecanismos utilizados pelos conselhos gestores podem ser ampliados como possibilidade de consolidar, de modo instrumental e político, os processos participativos e decisórios na gestão das políticas públicas.

Este estudo não esgota a discussão sobre instrumentos e mecanismos utilizados por conselhos de políticas na gestão pública. Entretanto, apresenta elementos que, em certa medida, podem subsidiar e ampliar o debate em torno dessa discussão.

\section{Referências}

ALMEIDA, Carla; TATAGIBA, Luciana. Os conselhos gestores sob o crivo da política: balanços e perspectivas. Serviço Social e Sociedade, v. 1, n. 109, p. 68-92, jan./mar. 2012.

AZEVEDO, Eder M. de. Os conselhos gestores no controle popular das políticas públicas. Jus Navigandi, v. 10, n. 887, p. 1-24, dez. 2005. Disponível em: <jus.com.br/revista/texto/7691>. Acesso em: 15 jan. 2012.

BRASIL. Constituição da República Federativa do Brasil: promulgada em 5 de outubro de 1988.

BRASIL. Diário Oficial da União. Lei $n^{\circ}$ 8.080/90. Dispõe sobre as condições para promoção, proteção e recuperação da saúde, a organização e o financiamento dos serviços correspondentes e dá outras providências. Brasília, 19 de setembro de 1990.

BRASIL. Diário Oficial da União. Lei no 10.257, de 10 de julho de 2001. Estatuto da Cidade e Legislação correlata. 2. ed. Brasília: Senado Federal, Subsecretaria de Edições Técnicas, 2002.

BRASIL. Ministério da Saúde. Decreto no 7.508, de 28 de junho de 2011: Regulamenta a Lei no 8.080, de 19 de setembro de 1990, para dispor sobre a organização do Sistema Único de Saúde — SUS, o planejamento da saúde, a assistência à saúde e a articulação interfederativa, e dá outras providências. Brasília: MS/GM, 2011.

BRASIL. Ministério da Saúde. Portaria nº 399, de 22 de fevereiro de 2006: Divulga o Pacto pela Saúde 2006 - consolidação do SUS e aprova as Diretrizes Operacionais do Referido Pacto. Brasília: Ministério da Saúde, 2006.

BRASIL. Ministério da Saúde. Sistema de planejamento do SUS: uma construção coletiva: orientações gerais para a elaboração de instrumentos de planejamento. Brasília: Ministério da Saúde, 2009a.

Rev. Adm. Pública - Rio de Janeiro 49(4):1059-1079, jul./ago. 2015 
BRASIL. Ministério do Desenvolvimento Social e Combate à Fome. Planos de assistência social: diretrizes para elaboração. Brasília: Ministério do Desenvolvimento Social e Combate à Fome; São Paulo: Instituto de Estudos Especiais da Pontifícia Universidade Católica de São Paulo, 2008. (CapacitaSuas, v. 3).

BRASIL. Ministério do Desenvolvimento Social e Combate à Fome. Resolução no 33, de 12 de dezembro de 2012: aprova a Norma Operacional Básica do Sistema Único de Assistência Social — NOB/ Suas. Brasília: Diário Oficial, Seção 1, n. 2, p. 155, quinta-feira, 3 jan. 2013.

BRASIL. Ministério do Planejamento. Subsecretaria de Planejamento, Orçamento e Gestão. Documento de referência do Programa Nacional de Gestão Pública e Desburocratização (GesPública). Brasília: Seges, 2009b.

BRASIL, Flávia de P. D.; CARNEIRO, Ricardo; TEIXEIRA, Lucas M. G. Democracia e inclusão: novos marcos para o planejamento e as políticas urbanas no âmbito local a partir da Constituição Federal de 1988. Cadernos da Escola Legislação, v. 12, n. 18, p. 127-163, 2010.

BULLA, Leonia C.; LEAL, Maria L. M. A participação da sociedade civil no Conselho Municipal de Assistência Social: o desafio de uma representação democrática. Textos \& Contextos, v. 3, n. 3, p. 1-13, dez. 2004. Disponível em: <www.educacaoambiental.pro.br/victor/biblioteca/SocCivilnoCMun.pdf>. Acesso em: 21 out. 2014.

CORRÊA, Izabela M. Planejamento estratégico e gestão pública por resultados no processo de reforma administrativa do estado de Minas Gerais. Rev. Adm. Pública, v. 41, n. 3, p. 487-504, maio/jun. 2007.

CULAU, Ariosto A. Planejamento e orçamento como instrumentos de gestão. São Paulo: Fundap, 2004. Disponível em: <www.fundap.sp.gov.br/escola/PAvGestaoPublica/calendPAGP.htm>. Acesso em: 23 jan. 2013.

FERREIRA, Aurélio B. de H. Novo dicionário da língua portuguesa. 4. ed. Curitiba: Positivo, 2009.

GARCIA, Ronaldo C. PPA: o que não é e o que pode ser. Políticas Sociais: Acompanhamento e Análise, v. 1, n. 20, p. 431-456, 2012.

HOUAISS, Antônio; VILLAR, Mauro S.; FRANCO, Francisco M. de M. Minidicionário Houaiss da língua portuguesa. 3. ed. Rio de Janeiro: Objetiva, 2009.

KLEBA, Maria E.; WENDHAUSEN, Águeda. Empoderamento: processo de fortalecimento dos sujeitos nos espaços de participação social e democratização política. Saúde e Sociedade, v. 18, n. 4, p. 733-743, 2009.

LANDERDHAL, Maria C. et al. Resoluções do Conselho de Saúde: instrumento de controle social ou documento burocrático? Ciência \& Saúde Coletiva, v. 15, n. 5, p. 2431-2436, jan. 2010.

MACHADO, Cristiani V.; BAPTISTA, Tatiana W. de F.; LIMA, Luciana D. de. O planejamento nacional da política de saúde no Brasil: estratégias e instrumentos nos anos 2000. Ciência \& Saúde Coletiva, v. 15, n. 5, p. 2367-2382, 2010.

MINAYO, Maria C. de S. O desafio do conhecimento: pesquisa qualitativa em saúde. 10. ed. São Paulo: Hucitec, 2007. 
OLLAIK, Leila G.; MEDEIROS, Janann J. Instrumentos governamentais: reflexões para uma agenda de pesquisas sobre implementação de políticas públicas no Brasil. Rev. Adm. Pública, v. 45, n. 6, p. 1943-1967, nov./dez. 2011.

PAULO, Luiz F. A. O PPA como instrumento de planejamento e gestão estratégica. Revista do Serviço Público, v. 61, n. 2, p. 171-187 abr./jun. 2010.

RONCONI, Luciana F. de A.; DEBETIR, Emiliana; MATTIA, Clenia de. Conselhos gestores de políticas públicas: potenciais espaços para a coprodução dos serviços públicos. Contabilidade, Gestão e Governança, v. 14, n. 3, p. 46-59, set./dez. 2011.

SALIBA, Nemre A. das et al. Conselhos de saúde: conhecimento sobre as ações de saúde. Rev. Adm. Pública, v. 43, n. 6, p. 1369-1378, nov./dez. 2009.

SANTOS, Mauro R. M. dos. Políticas sociais: instrumentos para exigibilidade de direitos. In: SANTOS JUNIOR, Orlando A. dos (Org.). Políticas públicas e gestão local. Programa interdisciplinar de capacitação de conselheiros municipais. Rio de Janeiro: Fase, 2003. p. 71-74.

SILVA, Áquilas M. L. A. da; CASTRO, Marcos J. de; SERPA, Paulo (Org.). Planejamento orçamentário municipal: o PPA, a LDO e a LOA em perguntas e respostas. São Paulo: Fundação Prefeito Faria Lima - Cepam, 2006.

SILVA E OLIVEIRA, Virgílio C. da; PEREIRA, José R.; OLIVEIRA, Vânia A. R. de. Os conselhos gestores municipais como instrumentos da democracia deliberativa no Brasil. Cadernos EBAPE.BR, v. 8, n. 3, p. 422-437, set. 2010. Disponível em: <www.scielo.br/scielo.php?pid $=5167939512010000300004 \& s-$ cript $=$ sci_abstract\&tlng $=$ pt $>$. Acesso em: 21 jul. 2011.

VÁZQUEZ, María L. et al. Nível de informação da população e utilização dos mecanismos institucionais de participação social em saúde em dois municípios do Nordeste do Brasil. Ciência \& Saúde Coletiva, v. 10, n. Supl., p. 141-155, 2005.

Maria Elisabeth Kleba é doutora em filosofia e enfermagem e professora da Universidade Comunitária da Região de Chapecó (Unochapecó). E-mail: 1kleba@unochapeco.edu.br.

Dunia Comerlatto é doutora em serviço social e professora da Universidade Comunitária da Região de Chapecó (Unochapecó). E-mail: dunia@unochapeco.edu.br.

Kenia Munaretti Frozza é assistente social da Prefeitura Municipal de Coronel Freitas (SC). E-mail: keniafrozza@unochapeco.edu.br. 